\title{
Месторождения полезных ископаемых, землетрясения и методология интерпретации сейсмических данных
}

\section{Кузин А.М.}

Институт проблем нефти и газа РАН, Москва, amkouzin@ya.ru

Аннотация. Кислород организует химические связи во всех породообразующих минералах. Низкая поляризуемость атомов кислорода обеспечивает упругий и электромагнитный способы передачи энергии, а также определяет характер процесса разрушения. Упругие свойства являются доминирующим свойством, через которые в основном осуществляется энергетическое взаимодействие. Кислород входит в химический состав воды, тем самым, образуя общность свойств между горными породами и водными растворами. Кислородными и водородными связями ими объясняется фундаментальное свойство геосреды - конвергенция геологических процессов. Конвергентность геосреды позволила разработать единый подход к изучению сейсмичности и образованию месторождений флюидного генезиса. Конвекция - главный из механизмов преобразования литосферы, в котором вода служит ведущим элементом. С конвективными гидротермальными системами связаны процессы в очаге землетрясений и образование месторождений.

Ключевые слова: кислородные и водородные связи, сейсмический метод, конвергенция, скорость, методология, твердое тело, месторождения полезных ископаемых.

\section{Mineral deposits, earthquakes and methodology of seismic data interpretation}

\author{
Kouzin A.M. \\ Oil and Gas Research Institute RAS, Moscow, amkouzin@ya.ru
}

\begin{abstract}
Oxygen produces chemical bonds in all rock-forming minerals. Low atomic polarizability of oxygen provides elastic and electromagnetic transfer of energy and determines the nature of the destruction process. Elastic properties are the dominant characteristic feature that contributes to the energy interaction. Oxygen is a part of the chemical composition of water, thus making properties of rocks and aqueous solutions similar. Oxygen and hydrogen bonds explain the fundamental property of the geological environment - the convergence of geological processes. The convergence of the geological environment made it possible to develop a unified approach to the study of seismicity and the formation of deposits of the fluid genesis. Convection is the main mechanism of transformation of the lithosphere, where water serves as a leading element. Convective hydrothermal systems are associated with processes in the seismic focus and the formation of deposits.
\end{abstract}

Key words: oxygen and hydrogen bonds, seismic method, convergence, speed, methodology, solid, mineral deposits

Сейсмический метод применяется в изучении геологической среды при проведении как инженерных работ, так и региональных и сейсмологических исследований. Это вызвано тем, что в отличие от других геофизических методов, данные сейсмических наблюдений носят не только качественный, но и количественный характер. Природа эффективности сейсмического метода определяется кислородными и водородными связями.

Кислород организует химические связи во всех породообразующих минералах. Низкая поляризуемость атомов кислорода обеспечивает упругий и электромагнитный способы передачи энергии, а также определяет характер процесса разрушения. Именно упругие свойства являются доминирующим свойством, через которые в основном осуществляются энергетическое взаимодействие.

Кислород входит в химический состав воды, тем самым образуя общность свойств (в том числе упругих) между горными породами и водными растворами. У воды самая высокая диэлектрическая проницаемость. Вода является самым сильным растворителем. С конвективными гидротермальными системами связаны процессы в очаге землетрясений и образование месторождений.

Многообразие в образовании водородных и кислородных связей определяет многообразие в развитии структуры, вещества и процессов в геологической среде, их подобие и схожесть. Единство 
растворителя, каким для абсолютного большинства полезных ископаемых флюидного генезиса является вода в виде $\mathrm{OH}-$ или $\mathrm{H}_{2} \mathrm{O}$, обуславливает общие условия локализации полезных ископаемых. В отличие от газа, вода обладает в десятки раз большей диэлектрической постоянной, за счет этого она проникает в кристаллическую решетку минералов и способствует разрушению горной породы без приложения внешнего напряжения. Эффект уменьшения прочности твердого тела в результате адсорбции, хемосорбции, смачивания и других физико-химических взаимодействий (эффект П.А. Ребиндера) установлен для твердых тел разного состава.

Вариации кислородных и водородных связей несут информацию об изменении структуры и состава геологической среды, ими объясняется фундаментальное свойство геосреды - конвергенция геологических процессов.

Конвергентность в геологической среде ярко проявляется в разрушении горных пород. М.А. Садовским была установлена закономерность соседних уровней иерархии неоднородностей разных масштабов, которая состояла в том, что «...отношение ее характерных размеров соседних уровней дают приблизительно одно и то же число 3.5 , тем самым система неоднородностей проявляет подобие на различных масштабах. Законы, определяющие строение неоднородностей на разных ступенях иерархической системы, имеют существенные общие черты при огромной, около 9 порядков, разнице масштабов и независимо от конкретных условий образования неоднородностей» (Садовский, 1979). В дальнейшем им с соавторами были показаны аналогии между землетрясениями и фазовыми переходами 2-го рода, сходство поведения твердого тела при малых скоростях деформации (крипе) и вязкой жидкости.

Идея о конвергентности рудных формаций впервые была высказана В.И. Смирновым (1960) применительно к колчеданным месторождениям. Им было показано, что, несмотря на общность геологических условий нахождения этих месторождений, удивительную устойчивость их минерального состава и строения рудных залежей, формировались они в разных, и даже в резко различных обстановках. Одни колчеданные месторождения образовались в морских бассейнах при седиментации сульфидного вещества, вынесенного в придонную область в процессе подводной гидротермальной деятельности. Другие формировались среди вулканогенных пород метасоматическим путем под воздействием серосодержащих паров и газов. Третьи возникли вследствие того, что в контурах рудных тел месторождений объединились метасоматические и вулканогенно-осадочные процессы. Конвергентность обнаруживается и в подобии условий залегания месторождений углеводородов и рудной минерализации (Поспелов, 1967).

Наиболее ярко конвергенция проявляется для углеводородов. Существуют два диаметрально противоположных взгляда: миграционно-осадочная гипотеза и неорганическая, глубинная. Полигенез углеводородов может рассматриваться как проявление конвергентности.

Конвергентность в локализации и сохранении полезных ископаемых не только по вещественному преобразованию и структуре, но и по упругим свойствам среды. Она наблюдается в многообразии форм геологической среды, предопределяет относительный характер соотношений упругих свойств вмещающей среды и резервуара.

Химические элементы и соединения в разных формах участвуют в кругообороте между различными глубинными уровнями, от осадочного чехла до мантии включительно. Мощность мантии составляет приблизительно 2900 км, наибольшая мощность земной коры - около 80 км, в среднем 30-40 км. То есть, мощность коры составляет меньше 1.5 \% от мощности мантии. Конвекция является одним из наиболее значимых механизмов преобразования литосферы. Конвекция установлена на различных масштабах и глубинных уровнях геологической среды от мантии и до самых верхов разреза. Существования мантийной конвекции приводит к необходимости совместного рассмотрения эндогенной и экзогенной составляющих многих геологических процессов. В качестве наиболее яркого примера глубинной конвекции можно привести изотопный состав алмаза. У большинства алмазов изотопный состав углерода совпадает с изотопным составом углерода земной коры (Галимов, 1988). Максимальная интенсивность конвекции наблюдается в верхней части земной коры за счет воды и её растворов. 
Перемещение флюидных потоков можно рассматривать как процесс релаксации упругой энергии в среде. Как правило, многие флюидные процессы связаны с механически жесткими неоднородностями. Жесткое тело во флюидных процессах выполняет следующие две функции: 1 - энергетический барьер (фильтр), поддерживающий определенные стационарность и интенсивность протекания геологических процессов при тектонической активизации; 2 - генератор и преобразователь упругой энергии в энергию физико-химических превращений вещества.

Модели твердого тела наиболее полно отвечает модель твердого тела со структурой (Родионов и др., 1986). В этом теле равномерно рассеяны разномасштабные неоднородности, расстояния между неоднородностями каждого размера много больше их собственного размера. При постоянной скорости деформации такого тела появляется новый параметр с размерностью длины, твердое тело приобретает зависимость от масштаба. Для всякого тела можно подобрать такую низкую скорость деформации, при которой оно разрушаться не будет, в рамках модели это соответствует крипу.

При высокой скорости деформации сложение неупругих и упругих напряжений приводит к увеличению эффективной прочности (динамическая прочность). Условие пропорциональности скорости релаксации величине напряжений и обратной пропорциональности размеру неоднородности применительно к реальной среде может быть интерпретировано как развитие в каждом элементарном объеме среды преимущественно самой длинной трещины, независимо от того, развивается она как равновесная или как неравновесная. Развитие наиболее крупной трещины ведет к сохранности блоков пород, примыкающих к трещине, в том числе служащих резервуарами для полезных ископаемых. Разрывные нарушения как бы «обтекают» более жесткую неоднородность, на которой или в которой может быть резервуар. Повышение трещиноватости обуславливает снижение модуля упругости пород. В зонах разломов напряжения резко снижаются (в 2-2.5 раза), а в породах, расположенных вблизи разломов, - возрастают в 1.3 раза. Зона повышенных напряжений распространяется на расстояние, в 1.5-3 раза превышающее мощность зоны дробления тектонического нарушения (Кузин, 2015). В экспериментах по формирования узлов разломов (Ружич, 1986) перед образованием поперечной трещины происходило упрочнение образца.

Образование зон упрочнения в среде может происходить не только при неупругом деформировании, но и при флюидизации. За счет быстрого увеличения трещинно-пористого пространства флюидное давление падает, что приводит к увеличению эффективного давления и уменьшению кулоновых напряжений при сохраняющемся уровне девиаторных напряжений. При этом происходит некоторое уменьшение внутреннего сцепления ненарушенных участков горной породы, а из-за усилившегося всестороннего обжатия данная область упрочняется, что позволяет рассматривать ее как жесткое включение (Добровольский, 1991).

В статическом состоянии жесткое тело формирует разность вертикальных напряжений между его кровлей и подошвой (Теор. основы.., 1986), Этим объясняется способность жесткого тела «притягивать» флюидные потоки. Разделение геологической среды по упругости на мягкие и жесткие неоднородности позволяет выделить структуры миграции и локализации флюида.

Одним из фундаментальных вопросов в изучении очага землетрясений является проблема накопления упругой энергии. Обычно рассматривается два варианта решения: первое - это «зацеп» на более жестком включении при скольжении тектонических блоков вдоль шва, и второе - накопление упругой энергии во всем объеме контактирующих тектонических блоков; последнее физически более предпочтительно. Накопление упругой энергии во всем объёме тектонического блока может реализоваться при условии относительной однородности его упругих свойств. Кислородные и водородные связи определяют не только способ (преимущественно упругий) передачи энергии, но и тип разрушения. Однородность массива пород или его частей, в свою очередь, может реализоваться вследствие развития наиболее крупных трещин в тектоническом блоке. Деформирование блока вызовет упорядоченность структурных свойств, появление анизотропии упругих свойств, а это означает переход модели твердого тела со структурой (Родионов и др., 1986).

О корреляции сейсмичности с рудными месторождениями эндогенного происхождения известно достаточно давно (Goldberg et al., 2007; Sibson, 1987). Сейсмические события регулярно фик- 
сируются в рудных узлах Воронежского кристаллического массива, Хибин и др. Сейсмический процесс контролируется относительно более упругой или жесткой неоднородностью среды. На её границах или в ней самой концентрируется и диссипирует в окружающее пространство упругая энергия. Другой общей чертой сейсмического процесса является присутствие газообразной флюидной фазы, ответственной за накопление упругой энергии. Газообразная фаза, заполняя поры и трещины, обеспечивает накопление упругой энергии и взрывной характера её выделения. Жидкая фаза создает гидравлическую связь между целиками массива пород и в то же время уменьшает сцепление на контакте зерен, увеличивая вероятность проскальзывания. Нарушение баланса между перечисленными факторами ведет к сейсмическому событию. Жидкая фаза служит фактором снижения порогового значения для сейсмического события и не является определяющим фактором.

Конвергентность процессов в геологической среде, обусловленная кислородными и водородными связями, позволила разработать единый подход к изучению сейсмичности и образованию месторождений флюидного генезиса. Проявления сейсмичности и месторождения флюидного генезиса имеют следующие общие черты. Процессы происходят на границе разноупругих сред, в более твердой или более упругой среде. Газообразный «сухой» флюид определяет накопление избыточной упругой энергии, «водный» флюид - порог ее диссипации. Процессы образования месторождений и сейсмичности являются импульсным откликом на тектоническую активизацию геологической среды.

Жесткие неоднородности следующим образом отображаются в скорости сейсмических волн: 1 - относительно повышенными значениями скорости продольных волн (Vp); 2 - относительно повышенными значениями скорости продольных (Vp) волн и поперечных (Vs) волн; 3 - относительно повышенными значениями скорости поперечных (Vs) волн и пониженными значениями скорости продольных (Vp) волн; 4 - относительно «нормальными» значениями скорости поперечных (Vs) волн при относительно пониженных значениях скорости продольных $(\mathrm{Vp})$ волн.

Анализ экспериментальных данных дает основание считать, что процессы флюидизации играют не меньшую роль в изменении параметров и характеристик сейсмического поля, чем вещественный состав, а во многих случаях и превалируют над ним. Например, по результатам измерения упруго-деформационных свойств осадочных и кристаллических пород ни в одной породе не было зарегистрировано уменьшение Vp после насыщения, а для гранитоидов характерным оказалось ее увеличение вплоть до 22 \% (Воларович и др., 1979). Причем изменение значений Vp/Vs между сухими и водонасыщенными образцами, рассчитанные по данным из этой работы, превосходят изменение $\mathrm{Vp} / \mathrm{Vs}$ между кислыми и основными породами даже по сравнению с теоретической зависимостью $\mathrm{Vp} / \mathrm{Vs}$ от $\mathrm{SiO}_{2}$ на $4 \%$.

Сейсмический метод позволяет наиболее полно по сравнению другими геофизическими методами охарактеризовать разрывные нарушения, а именно, выделить различные типы разрывных нарушений: 1 - залеченные минеральными растворами (промежуточные значения Vp между аномально низкими и средними для данного типа пород, пониженные значения $\mathrm{Vp} / \mathrm{Vs}) ; 2$ - открытые - проницаемые (низкие значения Vp и Vs). Кроме того, сейсмический метод предоставляет возможность определить преимущественный фазовый состав флюида в зонах разрывных нарушений, в залежах руд и углеводородов по Vp/Vs и интенсивности поля рассеянных волн.

Таким образом, создан единый методологический подход к интерпретации данных сейсмического метода. Возможности изучения геологической среды сейсмическим методом определяются кислородными и водородными связями. По сейсмическим данным может проводиться классификация на мягкие и жесткие неоднородности и, соответственно, прогноз преимущественного фазового состава флюида в этих неоднородностях.

Такой методологический подход позволяет разработать общую систему сейсмических исследований от полевых наблюдений до обработки и интерпретации данных. Дальнейшее развитие методологического подхода должно предполагать, что помимо упругого способа передачи энергии у кислорода существует ещё электромагнитный способ передачи энергии. В силу широкого распространения в земной коре углерода и кремния, необходимо учитывать их роль в упругом и электро- 
магнитном отклике геосреды. Можно предполагать, что анализ взаимодействия упругого и электромагнитного полей позволит подойти к решению проблемы концентрации и локализации рудной минерализации, а также углеводородов в определенных участках земной коры.

\section{Литература}

1. Воларович М.П., Томашевская И.С., Будников В.А. Механика горных пород при высоких давлениях. М. Изд-во: Наука. 1979. 152 с.

2. Галимов Э.М. Проблемы геохимии углерода // Геохимия. 1988. № 2. С. 258-279.

3. Добровольский И.П. Теория подготовки очага землетрясения. М. Изд.: ИФЗ АН СССР. 1991. 224 с.

4. Кузин A.M. Атомизм в естественном подходе изучения геосистем // Материалы IV Всероссийской конференции «Системный подход в геологии (теоретические и прикладные аспекты). Секция 4 Естественный подход при изучении природных геологических систем, Электронный журнал ГЕОРЕСУРСЫ. ГЕОЭНЕРГЕТИКА. ГЕОПОЛИТИКА. ВЫп 1 (3). Дата выхода 3 июля 2011 г.

5. Кузин А.М. О некоторых общих свойствах флюида в геологических процессах, явлениях и закономерностях (к обоснованию единой системы геолого-геофизического изучения недр). Ч. 1, 2 // Георесурсы, геоэнергетика, геополитика. 2015. Вып. 2 (12). http://oilgasjournal.ru/top-pages/last-issue.html.

6. Поспелов Г.Л. Элементы геологического подобия нефтяных и флюидогенных рудных месторождений // Геология и геофизика. 1967. № 11. С. 3-22.

7. Родионов В.Н., Сизов И.А., Цветков В.М. Основы геомеханики. М. Изд-во: Недра. 1986. 301 с.

8. Ружич В.В. Разломные узлы, их механизм и роль в становлении напряженного состояния земной коры Байкальской рифтовой зоны // Математические экспериментальные методы в дизъюнктивной тектонике. М. Изд-во: Наука. 1986. С. 68-94.

9. Садовский М.А., Болховитинов Л.Г., Писаренко В.Ф. О свойствах дискретности горных пород // Изв. АН СССР. Физика Земли. 1982. № 12. С. 3-19.

10. Теоретические основы инженерной геологии. Геологические основы (под ред. акад. Е.М. Сергеева). М. Изд-во: Недра. 1986. 332 с.

11. Goldberg I.S., Abramson G.J., Haslam C.O., Los V.L. Depletion and enrichment zones in the Bendigo gold field: a possible source of gold and implications for exploration. Society of Economic Geologists, Inc. Economic Geology. 2007. V. 102. P. 745-753.

12. Sibson R.H. Earthquake rupturing as a hydrothermal mineralizing agent. Geology. 1987. V. 15. P. 701-704. 